\title{
Case study B: Universal basic income grant in theory and practice
}

\author{
Brian Mathebula
}

\section{INTRODUCTION}

The idea of a basic income grant (BIG) is not new and there are ongoing debates internationally as well as nationally in low- and middle-income countries just like in high-income countries of a BIG as a social protection policy option. The challenge is that there are different conceptualisations, which conflates and muddles the understanding.

In the context of social assistance provision, a universal basic income grant (UBIG) is often compared and contrasted against targeted cash transfers (CTs). This case study systematically presents the arguments for targeted CTs and UBIGs. The value of the case study is that it systematically brings together these arguments, highlighting the variations in UBIG applications, including the evidence and actual impact of UBIG experiments. The structure of the case study is as follows: Section 2 simultaneously contrasts and compares the arguments for targeted CTs and UBIG. Section 3 discusses UBIG experiments, as well as presenting the evidence on the application of the UBIG idea, and Section 4 concludes.

\section{ARGUMENTS IN SUPPORT OF TARGETED CASH TRANSFERS AND UNIVERSAL BASIC INCOME GRANTS}

The UBIG idea is considered to be a radical proposal because it challenges the current practice in the provision of social protection schemes in the form of CTs, which are almost always targeted. This section presents the arguments for and against. We define a UBIG as a periodic CT paid unconditionally on an individual basis to all members of society without a means test or requirement to work (Offe 2008; van Parijs 1995; Wright 2004, 2006). A CT refers to the regular and predictable non-contributory social transfer, provided either on a universal basis or targeted based on established eligibility criteria and/or unconditional or conditional on behaviour (DFID 2011).

\subsection{Arguments for Targeted Cash Transfers}

In the last two decades, there has been an exponential increase in the number of low- and middle-income countries that have increased access to CTs as part of their poverty reduction and social protection strategy (Bastagli et al. 2016). Impact evaluation studies have found a positive link between access to CTs and positive outcomes in areas of well-being such as education, health and poverty across a large number of countries (Samson et al. 2004; Baird et al. 2014; Bastagli et al. 2016; Davis et al. 2016). These targeted CTs provide income support, redistribute wealth and promote inclusive growth (Bastagli et al. 2016; Barrientos and Hulme 
2010; Samson et al. 2004) and reduce income inequality (Schiel et al. 2016; Finn et al. 2010; Gaspirini and Lustig 2011).

The targeting of CTs is viewed as an efficient use of limited resources, especially in lowand middle-income countries where financial constraints are more pronounced and social protection competes with other equally important policy areas (Slater and Farrington 2009; Mcord 2009). Targeted CTs allow for limited resources to be reserved on a 'needs basis', whilst minimising inclusion errors, i.e. it is not to be transferred to individuals who do not need it such as the middle- and upper-income groups. Targeting allows CTs to reach excluded groups (de la Brière and Rawlings 2006) and more money can be transferred to these groups and thus increase the impact of the CT.

The 2030 Sustainable Development Goals emphasise the need to close the social protection gap, especially Target 1.3 , through nationally appropriate social protection schemes and measures, including income floors. ${ }^{1}$ In middle-income countries, where there is low social protection coverage due to the dominance of social insurance schemes for individuals in formal employment, CTs have played an important role in reducing the social protection coverage gap (Bastagli 2013). A targeted CT is best suited for raising and broadening existing income floors (Greenstein 2019).

Despite the positive impact of targeted CTs, they are often associated with high administrative costs such as targeting, meeting and monitoring conditions, bureaucracy, overhead costs and corruption (Devereux et al. 2015). There is criticism of conditional CTs, especially in contexts where social protection in the form of CTs is promoted as a right, including the 1948 Universal Declaration of Human Rights. It is problematic to promote access to citizen CTs as a 'right', whilst also threatening access to the same 'right' if they fail to meet predetermined behavioural compliance 'conditions' (Freeland 2007).

\subsection{Arguments for a Universal Basic Income Grant}

The universal approach in a UBIG would increase the take-up or participation in CT programmes, especially amongst the poor and vulnerable groups (Atkinson 2011). In other words, a UBIG eliminates exclusion errors, i.e. they do not reach all eligible people (Devereux et al. 2015; Bastagli et al. 2016; Baird et al. 2014). A UBIG creates inclusive social protection systems (van Parijs 1995; Wright 2006; Widerquist 2018) and reduces the social stigmatisation of poor households or vulnerable groups as a result of participation in safety net programmes (Sabates-Wheeler and Devereux 2008; Simons et al. 2018; Slater and Farrington 2009).

A UBIG transfers cash to every member of society, and this is viewed as creating social equality and equity (Standing 2008; Wright 2006; van Parijs 1995; van Parijs and Vanderborght 2017; Danson et al. 2012), as well as fostering inclusion as it benefits every member of society (Danson et al. 2012; Standing 2008; van Parijs and Vanderborght 2017; Wright 2006). A UBIG would increase participation in social activities and thus decrease social isolation of low-income people (Widerquist 2018) and reduce income inequality and gender inequality, including inequality between age groups and people with disabilities (Standing 2017).

A UBIG removes the administrative hurdles such as the need for CT recipients to prove their poverty. A UBIG does away with high administrative costs, such as those caused by

https://sdgs.un.org/goals. 
targeting, meeting and monitoring behavioural compliance (Devereux et al. 2015; Standing 2008). The universal approach in UBIG makes it more transparent because everyone is eligible and, hence, less susceptible to corruption (Widerquist 2018; Barnejee et al. 2019) and it reduces the discretionary power of administrators, especially when relying on proxy indicators for establishing eligibility.

A UBIG would create a minimum income floor, which every member of society would not fall under. The minimum income floor created by a UBIG would also empower both unionised and non-unionised individuals to refuse exploitative working conditions (Widerquist 2018; Standing 2008; Wright 2006). The income guarantee provided by a UBIG would act as a labour market incentive, and liberate individuals ('individual freedoms') of having to enter the labour market in order to satisfy their basic needs (van Parijs 1995; van Parijs and Vanderborght 2017).

Similarly, there are several criticisms labelled against the UBIG proposal. First, not every individual can take advantage of the 'real freedoms' such as the disabled, who may require more resources to achieve equivalent freedoms (Andersen 2016). Second, the income guarantee provided by a UBIG would incentivise individuals to undertake jobs they are intrinsically motivated to undertake with negative effects on the labour supply (Pech 2010). Third, despite various proposals for financing a UBIG, it would be expensive, and an increase in general taxes to finance it would likely be met with opposition from middle- and upper-income groups (EPRS 2016). Fourth, there is a lack of consensus as to whether a UBIG would either complement, replace and/or supplement existing welfare benefits (Ortiz and Acuna-Ulate 2018).

\section{UNIVERSAL BASIC INCOME GRANT EXPERIMENTS: EMERGING EVIDENCE AND CHALLENGES}

In recent years, the number of experiments has increased in both developing and developed country contexts. This section commences with a discussion on the variations in application of a UBIG before turning to the evidence and the actual impact of existing UBIG programmes.

\subsection{Discussing the Case Study Experiments}

Table B.1 provides an overview of selected UBIG experiments in high-, low- and middle-income countries. Table B.1 further demonstrates that existing UBIG programmes differ in their primary interest, coverage (target group) and generosity.

There are limitations in terms of a comparative review of the emerging evidence for five reasons. First, not all the experiments explicitly claim to be basic income experiments, such as the experiment in the Netherlands (Widerquist 2018). Second, experiments have not been universal but rather targeted, and undertaken on a short-term basis, as compared to the long-term commitment envisioned by UBIG proponents (Barnejee et al. 2019). Third, in the design, randomised control trials (RCTs) ${ }^{2}$ are included in the experiment in Kenya, Spain, the Netherlands and Canada (Widerquist 2018). This means the impact evaluation in these experiments are not undertaken with the same rigour as experienced with CTs, thus making it diffi-

2 In Canada, both the treatment and control group are randomly selected, as opposed to eligibility based on being unemployed in Finland. 


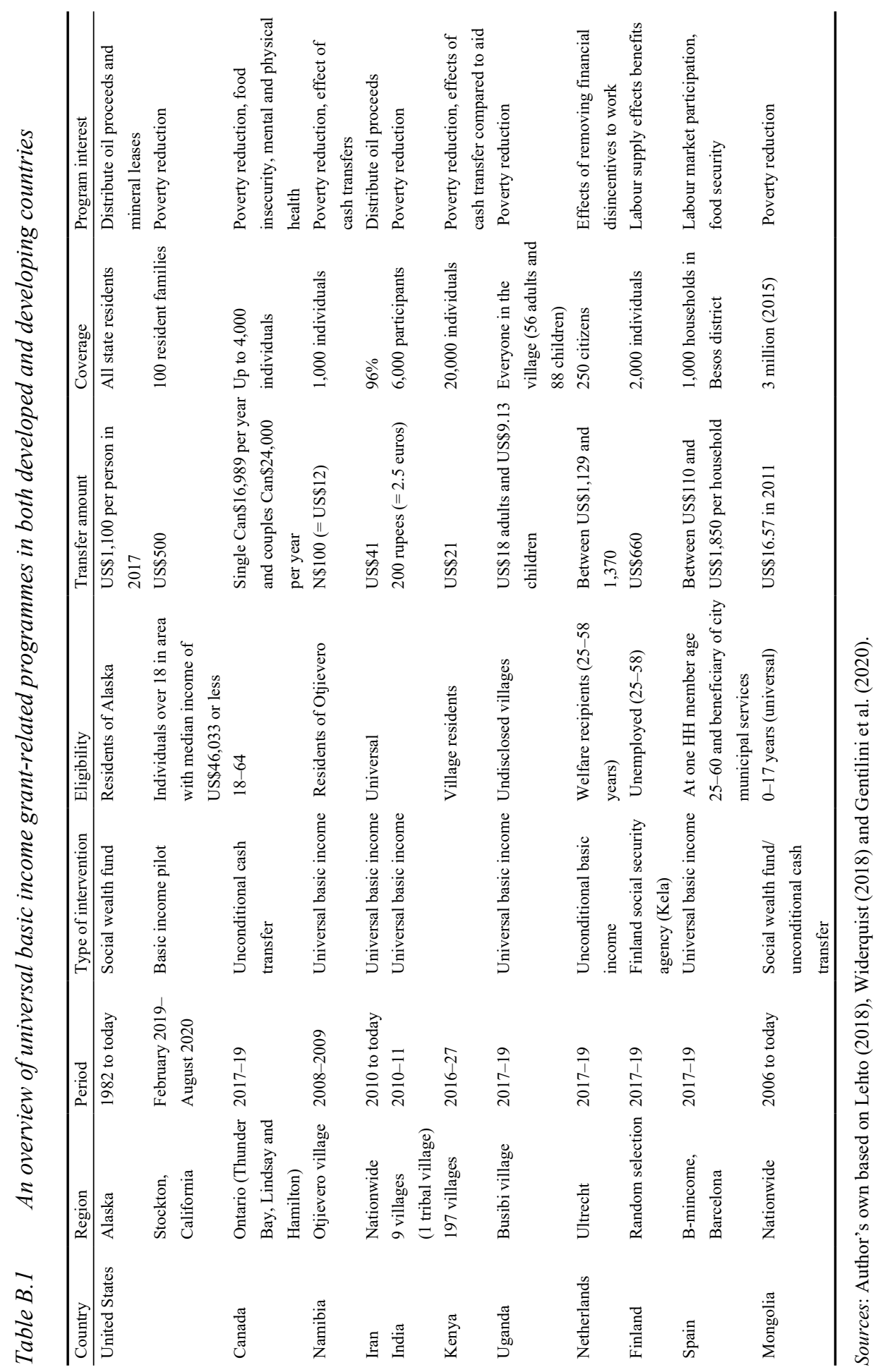


cult to draw conclusions on the impact. Fourth, the experiments are driven by context-specific interests, which suggests that in practice there are different understandings of what constitutes a UBIG. Fifth, the variations have significantly contributed to the lack of consensus in terms of the understanding of a UBIG (Widerquist 2018), as well as the characteristics or dimensions of a UBIG.

There are similarities in terms of the target groups in the UBIG experiments. In all the experiments there is an explicit focus on vulnerable groups, such as the poor, children, ${ }^{3}$ unemployed and recipients of other targeted social benefits. It is only in Finland, the Netherlands and Spain where participants are beneficiaries of other targeted social programmes. The experiments in Finland, Canada, Spain and the Netherlands are targeted at working-age individuals who are labour-market constrained. The focus is on addressing challenges related to the labour market such as labour participation or reintegration. This could be viewed as the UBIG seeking to replace the existing welfare system, whilst testing conditionalities. In the low- and middle-income countries there is an explicit interest in poverty alleviation.

\subsection{Universal Basic Income Grant Experiments: Evidence and Actual Impact of Experiments}

Despite the impact evaluations not being undertaken with the same rigour as CTs, there were still positive impacts found on poverty reduction, food security and consumption patterns in Namibia (NANGOF 2009; Haarmann and Haarmann 2015), India (Schjoedt 2016; BIEN 2018), Mongolia (Yeung and Howes 2015) and Spain. ${ }^{4}$ There was reduced material deprivation in Spain, India (Schjoedt 2016) and Namibia (Haarmann and Haarmann 2015), as individuals were able to procure items or invest in household-related infrastructure.

UBIG proponents claim that a UBIG would act as a labour market incentive (van Parijs 1995; van Parijs and Vanderborght 2017). Studies found increased productive activity and reduction in child labour in India (BIEN 2018), increased economic activity in Namibia as some of the money transferred was also used to search for employment (NANGOF 2009; Haarmann and Haarmann 2015). There was no significant impact on labour supply in Alaska and no overall decrease in employment or overall number of hours worked in Alaska (Jones and Marinescu 2018). In Finland the test group did not enter the labour market or earned more than members in the control group (Kangas et al. 2019).

There were negative effects in India and Alaska in terms of the adequacy of the amount transferred. It was found that the amount transferred was insufficient to meet the basic needs in Alaska (Widerquist and Sheahan 2012) and inadequate to allow for a decent standard of living (Standing 2008). In Mongolia, there were reported challenges related to the implementation and sustainability of the programme (Yeung and Howes 2015).

\footnotetext{
The Mongolian experiment was universal for all children aged between 0 and 17 .

4 https://basicincome.org/news/2019/09/spain-the-barcelona-b-mincome-experiment-publishes-its -first-results/.
} 
Although a UBIG is often compared and contrasted against targeted CTs, the arguments for and against both approaches suggest there are positive links in areas of well-being. The impact evaluations confirm positive links when accessing both CTs and UBIGs, especially in poverty reduction, which suggest that predictability and reliability of the transfer is what matters the most. There was also no evidence found to suggest that a UBIG would lead to individuals absconding from labour market participation in favour of leisure. From an academic and policymaker perspective, the UBIG experiments do not shed light on what constitutes a UBIG (including characteristics/dimensions) because of the variations in the ideological underpinnings, programme design and interest and delivery channels in high-, middle- and low-income countries.

\section{REFERENCES}

Andersen, E. (2000). Optional feedoms. In K. Widerquist, J.A. Noguera, Y. Vanderborght and J. De Wispelaere (eds), Basic Income: An Anthology of Contemporary Research. Hoboken, NJ: Wiley.

Atkinson, A. (2011). Basic Income: Ethics, Statistics and Economics. Oxford: Nuffield College.

Baird, S., F.H.G. Ferreira, B. Özler and M. Woolcock (2014). Conditional, unconditional and everything in between: A systematic review of the effects of cash transfer programmes on schooling outcomes. Journal of Development Effectiveness 6 (1), 1-43.

Barnejee, A., P. Niehaus and S. Tavneet (2019). Universal Basic Income in the Developing World. Cambridge, MA: MIT Press.

Barrientos, A. and D. Hulme (2010). Social protection for the poor and poorest in developing countries: Reflections on a quiet revolution. Oxford Development Studies 38 (1), 439-56.

Bastagli, F. (2013). Feasibility of social protection schemes in developing countries. European Parliament. Directorate-General for External Policies of the Union. www.europarl.europa.eu/meetdocs/2009 2014/documents/deve/dv/study_social_protecti/study_social_protection.pdf

Bastagli, F., J. Hagen-Zanker, L. Harman, V. Barca, T. Schmidt, G. Sturge and L. Pellerano (2016). Cash transfers: What does the evidence say? A rigorous review of programme impact and of the role of design and implementation features. www.odi.org/sites/odi.org.uk/files/resource-documents/10749.pdf

BIEN (2018). About basic income. https://basicincome.org/about-basic-income/

Danson, M., R. McAlpine, P. Spicker and W. Sullivan (2012). The Case for Universalism: An Assessment of the Evidence on the Effectiveness and Efficiency of the Universal Welfare State. Glasgow: Jimmy Reid Foundation.

Davis, B., H. Handa, N. Hypher and N. Rossi (eds) (2016). From Evidence to Action: The Story of Cash Transfers and Impact Evaluation in Sub-Saharan Africa. Oxford: Oxford University Press.

de la Brière, B. and L.B. Rawlings (2006). Examining conditional cash transfer programs: A role for increased social inclusion? Social Protection and Labor Discussion Paper, No. 0603. Washington, DC: World Bank. https://openknowledge.worldbank.org/handle/10986/20204

Devereux, S., E. Masset, R. Sabates-Wheeler, M. Samson and A.-M. Rivas (2015). Evaluating the targeting effectiveness of social transfers: A literature review. CSP Working Paper, Vol. 012. Brighton: IDS.

DFID (2011). Cash transfers. Evidence Paper-Policy Division. www.who.int/alliance-hpsr/alliancehpsr dfidevidencepaper.pdf

EPRS (2016). Basic income: Arguments, evidence, prospects. Briefing. European Parliament. www .europarl.europa.eu/RegData/etudes/BRIE/2016/586679/EPRS_BRI(2016)586679_EN.pdf

Finn, A., M. Leibbrandt, J. Argent and I. Woolard (2010). Trends in South African income distribution and poverty since the fall of Apartheid. www.oecd.org/social/soc/45041981.pdf

Freeland, N. (2007). Superfluous, pernicious, atrocious and abominable? The case against conditional cash transfers. Institute for Development Studies (IDS), 38 (3). 
Gasparini, L. and N. Lustig (2011). The rise and fall of income inequality in Latin America. Centro de Estudios Distributivos, Laborales y Sociales. www.researchgate.net/publication/228377497_The Rise and Fall of Income Inequality in Latin America

Gentilini, U., M. Grosh, J. Rigolini and R. Yemtsov (2020). Exploring Universal Basic Income: A Guide to Navigating Concepts, Evidence, and Practices. Washington, DC: World Bank. https:// openknowledge.worldbank.org/handle/10986/32677

Greenstein, B. (2019). Commentary: Universal Basic Income May Sound Attractive But, if It Occurred, Would Likelier Increase Poverty Than Reduce It. Washington, DC. Center for Budget and Policy Priorities. www.cbpp.org/sites/default/files/atoms/files/5-31-16bud.pdf

Haarmann, C. and D. Haarmann (2015). Relief Through Cash: Impact Assessment of the Emergency Cash Grant in Namibia. Windhoek: Desk for Social Development.

Jones, D. and E. Marinescu (2018). The labor market impacts of universal and permanent cash transfers: Evidence from the Alaska permanent fund. SSRN Electronic Journal. https://doi.org/10.2139/ssrn .3118343

Kangas, O., J. Signe, S. Miska and Y. Minna (eds) (2019). The Basic Income Experiment 2017-2018 in Finland: Preliminary Results. Helsinki: Ministry of Social Affairs and Health. http://julkaisut .valtioneuvosto.fi/bitstream/handle/10024/161361/Report_The\%20Basic\%20Income\%20Experiment \%2020172018\%20in\%20Finland.pdf

Lehto, O. (2018). Basic income around the world: The unexpected benefits of unconditional cash transfers. London: Adam Smith Institute. https://static1.squarespace.com/static/56eddde762cd941 3e151ac92/t/5a5f54ff53450ae87509190a/1516197120863/Universal+Basic+Income.pdf

Mcord, A. (2009). Cash transfers: Affordability and sustainability. Project Briefing no 30. www .researchgate.net/publication/239590004_Cash_transfers_Affordability_and_sustainability

NANGOF (2009). Making the difference! The BIG in Namibia: Basic income grant pilot project assessment report. April.

Offe, C. (2008). Basic income and the labor contract. Basic Income Studies 3 (1). https://doi.org/10.2202/ 1932-0183.1100

Ortiz, B. and N. Acuna-Ulate (2018). Universal basic income proposals in light of ILO standards: Key issues and global costing. CSP Working Paper No. 62. https://socialprotection-humanrights.org/wp -content/uploads/2018/07/55171.pdf

Pech, W.J. (2010). Behavioral economics and the basic income guarantee. Basic Income Studies 5 (2). https://doi.org/10.2202/1932-0183.1167

Sabates-Wheeler, R. and S. Devereux (2008). Transformative social protection: The currency of social justice. In A. Barrientos and D. Hulme (eds), Social Protection for the Poor and Poorest.Palgrave Studies in Development. London: Palgrave Macmillan, 66-84. https://doi.org/10.1057/978-0-230-58309-2 4

Samson, M., U. Lee, A. Ndlebe, K. MacQuene, I. van Niekerk, V. Ghandhi, T. Harigaya and C. Abrahams (2004). The social and economic impact of South Africa's social security system. EPRI Research Paper 37. Cape Town: EPRI.

Schiel, R., M. Leibbrandt and M. Lam (2016). Assessing the impact of social grants on inequality: A South African case study. WIDER Working Paper 160/2014 UNU-WIDER. https://doi.org/10 .35188/UNU-WIDER

Schjoedt,R.(2016).India's basicincomeexperiment.DevelopmentPathways. www.developmentpathways .co.uk/wp-content/uploads/2016/04/Indias-Basic-Income-Experiment-PP21-1.pdf

Simons, A.M.W., I. Houkes, A. Koster, D.A.I. Groffen and H. Bosma (2018). The silent burden of stigmatisation: A qualitative study among Dutch people with a low socioeconomic position. BMC Public Health 18, 443.

Slater, R. and J. Farrington (2009). Cash transfers: Targeting. Project Briefing No. 27. www.odi.org/ sites/odi.org.uk/files/odi-assets/publications-opinion-files/4604.pdf

Standing, G. (2008). How cash transfers promote the case for basic income. Basic Income Studies 3 (1). https://doi.org/10.2202/1932-0183.1106

Standing, G. (2017). Basic Income. London: Penguin Books.

van Parijs, P. (1995). Real Freedom for All: What (if Anything) Can Justify Capitalism? Oxford: Clarendon Press.

van Parijs, P. and Y. Vanderborght (2017). Basic Income: A Radical Proposal for a Free Society and a Sane Economy. Cambridge, MA: Harvard University Press. 
Widerquist, K. (2018). A Critical Analysis of Basic Income Experiments for Researchers, Policymakers, and Citizens. Basingstoke: Palgrave.

Widerquist, K. and A. Sheahan (2012). The United States: The basic income guarantee - past experience current proposals. In C. Murray and M. Pateman (eds), Basic Income Worldwide: Horizons of Reform. Basingstoke: Palgrave, 11-32.

Wright, E.O. (2004). Basic income, stakeholder grants, and class analysis. Politics and Society 32 (1), 79-87.

Wright, E.O. (2006). Basic income as a socialist project. Basic Income Studies 1 (1). https://doi.org/10 $.2202 / 1932-0183.1008$

Yeung, Y. and S. Howes (2015). Resources-to-cash: A cautionary tale from Mongolia. Australian National University. https://im4dc.org/wp-content/uploads/2015/09/Combined-Yeung.pdf 